\title{
Ensayo
}

\section{El mundo, espuma del tiempo en nuestra mano: chatear con Sergio (Roncallo-Dow)}

\section{Harvey Murcia Quiñones ${ }^{1}$ Carlos Andrés Arango²}

DOI: 10.5294/pacla.2020.23.s.3

Para citar este ensayo / to reference this essay / para citar este ensaio Murcia Quiñones, H. y Arango, C. A. (2020). El mundo, espuma del tiempo en nuestra mano: chatear con Sergio (Roncallo-Dow). Palabra Clave, 23(supl.), e23s3. https://doi. org/10.5294/pacla.2020.23.s.3

\section{Resumen}

Este trabajo presenta una re-visión analítica de una experiencia comunicativa entre amigos y colegas, motivado por la muerte de Sergio Roncallo-Dow. Desde la intuición suya de cómo otros lenguajes tecnológicos comenzaban a ser espacios de inspección intelectual, abordamos la reflexión de cómo los chats se convierten en lugares para aventurar tesis, realizar asociaciones libres y comentar los sucesos del mundo. Todo esto lleva de fondo la pregunta por la tecnología, la noción de medio y la filosofía como forma de vida, cercanos a Sergio y motores de pensamiento para nosotros en tanto amigos y colegas.

\section{Palabras clave}

Tecnología; lenguaje simbólico; medios electrónicos; filosofía. 


\section{Introducción}

Sabemos que Sergio estaría feliz si nos leyera afirmar que una significativa parte de su obra está en los chats. Allí, podríamos sostener conversaciones únicamente con gifs, debatir las relaciones entre los últimos discos del rock con la perspectiva benjaminiana del aura o corregir los memes filosóficos aparecidos la última semana. "Juegos de lenguaje", solía afirmar, entre la caricatura comunicativa y la sentencia filosófica.

El ser humano, el filósofo, el músico y el entusiasta de las telenovelas nunca estuvieron separados en Sergio. De hecho, el niño que coleccionaba figuras, el adolescente que tocaba rock, el universitario que devoraba libros y el adulto que se hacía preguntas profundas sobre el mundo convivían simultáneamente. De ahí que su mejor legado filosófico, una parte del cual se puede leer en la significativa producción bibliográfica que nos deja, fue, ante todo, su testimonio de la filosofía como una forma de vivir. Hacer de la vida una obra de arte se tornaba en él como algo menos platónico ${ }^{3}$ para convertirse en una performance más en la línea de un posible Heidegger ft. Wittgenstein.

En esa forma de estar-en-el-mundo, precisó constantemente de un estar-siendo-escritura, cuyos registros — multimodales - llegan de las más diversas formas hasta este presente desde el que hoy releemos comentarios en chats, artículos científicos y libros, tesituras cuyas formas de producción de sentido supo explorar en las más amplias dimensiones. La comunicación, la música y la filosofía surgen como un entorno en-medio del cual fluyó una notable visión del mundo: la comunicación como posibilidad de encuentro con el otro, la filosofía como pregunta por la concepción del sentidoen-el-mundo, la música como una fusión mediata de los conceptos imagen.

Si la filosofía es el espacio de construcción de conceptos (Deleuze y Guattari, 2006), encontrarnos de nuevo con los (hiper-, para-, archi-) textos de Sergio viene a ser la invitación a develar los sentidos que propician

3 Pese a que en varios de sus textos analizó respetuosamente mitos platónicos en clave de lectura del entramado técnico, desde Blumenberg alguna vez sentenció que, al final del día, la reconversión socrática del mito habría causado una suerte de encajonamiento discursivo por cuenta del logos que reorganiza lo mítico en compartimentos aleccionadores, y así desconoce su portentosa capacidad significativa (Roncallo-Dow, 2008a, p. 70). 
los entornos tecnológicos, cosa que, en su lectura, siempre fue una invitación a revisitar las nociones de lenguaje, medio y tecno-logía como tres notas armónicas cuyo acorde, esquivo, se tomó la tarea de rastrear en los chats, deconstruir en los textos, proseguir en la guitarra y desagregar en sus provocadoras clases, conferencias y conversaciones.

Así pues, como homenaje asumimos la tarea de revisitarlas, no en clave de inventario, análisis ilustrado o reconstrucción (tarea que requerirá tiempo y es ya una labor fijada en la agenda de los estudios en comunicación y filosofía), sino más desde el punto de vista de quienes fraguan entre las memorias del amigo que se fue (al menos en este registro físico al que damos en llamar el mundo real) para asir algo de sentido al mundo que ahora nos queda.

Nos proponemos una breve revisión del concepto de tecnología en clave de algunos de los guiños que Sergio marcó en su obra, idea desde la cual pretendemos rearmar el sentido que hizo para nosotros el descubrimiento del lenguaje como entorno humano y, por tanto, su íntima fusión con la idea de mundo como entorno, sin duda, uno de los temas a los que Sergio más dedicó horas de estudio, y gracias a las cuales nuestra comprensión del entorno tecnológico se despliega como un horizonte de sentido por re-descubrir. Releamos.

\section{Los fuegos (de lenguaje) de Prometeo}

Como se lee en su Más allá del espejo retrovisor: la noción de medio en Marshall McLuhan (Roncallo-Dow, 2011a), mientras que la técnica es un saber productivo, poiético, esto es, que hace-(en)-el mundo (p. 27), la tecno-logía implica un poder dar razón de ese saber hacer (pp. 34-50). Sin embargo, mientras la pregunta por lo técnico pareciera llevar a las funcionalidades objetuales, la clave tecno-lógica redescubre cómo la acepción tradicional que vincula lo técnico como una dimensión externa a lo humano desconoce la forma como, desde la mano hasta el lenguaje, toda extensión del hombre es ya un constructo técnico. En otras palabras, nuestra idea de mundo está mediada por las interjecciones de la técnica (sustantivo colectivo) (p. 28), si bien solo nos es permitido dar cuenta de esta conjunción cuando arribamos a un nivel de lectura tecno-lógico. 
$\mathrm{La} / \mathrm{s}$ tecnología/s han traído consigo un sinnúmero de nombres, significados e interpretaciones que se asocian, las más de las veces, a visiones excluyentes de sus usos y potencias; no es gratuito que cada transformación tecnológica proponga linderos semánticos, estéticos, políticos y comunicativos para mutar los procesos sociales con los que se fomenta y se fermenta la episteme social; sentidos que rebasan la Historia y que se explican en las historias de lo cotidiano, lo científico y lo informativo. Estas denominaciones se tienden como metáforas, toda vez que "las metáforas nunca son inocentes, poseen una riqueza de sentidos que superan su significado contextual y contaminan los márgenes de la palabra" (Sibila, 2013, p. 198).

La profusión de nombres y terminologías pudiera tenderse como una nube espesa que impida la visión. Será el lente tecno-lógico, es decir, el proponerse dar razón de esa inicial transparencia de lo técnico en lo social, lo que permita comprender los alcances de su presencia en el mundo, no tanto como un conteo de objetos, sino como su reconocimiento en tanto aroma del tiempo, una suerte de zeitgeist (noción inspiradora en el trabajo de Sergio; cfr. Roncallo-Dow, 2008, p. 77; 2011b, p. 131; Uribe-Jongbloed y Roncallo-Dow, 2013, pp. 189, 196, 198 y 199). Será el lente tecno-lógico lo que permita problematizar el sistema técnico como entramado de complejas relaciones de intercomunicación entre sus lógicas. Ante la dificultad que pudieran representar las jergas y las terminologías, convendría entonces arribar a lo tecnológico vía colisionarlo contra la poesía en su intento de asomarse a los límites del mundo: "las cosas son la espuma del tiempo en nuestra mano” (Barba Jacob, 2011, p. 18).

Se capta en las palabras del poeta colombiano una escritura introspectiva que despunta como destello en medio de la enorme transformación social futurista que ya se estaba viviendo en su época por cuenta de los cambios estructurales que asomaba la tecnología. Paradójicamente, estas numinosas palabras se convierten en un iluminador arribo, pequeña profecía de las fugas semióticas con las que hemos de trazar los cambios entre nuestra anterior percepción del mundo (estable, maciza, fija) en su tránsito ambivalente hacia algo móvil, huidizo, en permanente cambio. 
A día de hoy, varias décadas después de escritos los versos modernistas de Barba Jacob, las preguntas que se desprenden (como metáforas que caen sobre nuestros sentidos) de esta tecnologización acelerada de la vida atraviesan las distintas esferas del habitar, pues traen hasta nosotros evidentes cambios cuya verificación comprobamos en el espacio-tiempo cotidiano. Si elegir las palabras del poeta era una invitación a dejarse danzar por las reverberaciones del sistema técnico en sus ondulantes choques contra las paredes de nuestro mundo, hay que decir que ese irse de la espuma en nuestras manos sirve como imagen de cómo se nos escapa a menudo la participación de lo técnico en nuestra idea del mundo.

De hecho, la naturalidad con la que este transcurre desaparece tan pronto como un cambio irrumpe en el paisaje. Ese cambio, no avisado, le hace sondear al poeta citado eso de la "espuma del tiempo", en tanto que en el mundo de la vida nos abre espacios interregnos, no lugares donde crecen el extravío y la nostalgia. En concreto, solo hasta que un nuevo dispositivo altera las anteriores formas de darse el mundo, y nosotros en él, captamos, como quiebres en nuestras rutinas, como porosidad en nuestras identidades (Fierro y Roncallo-Dow, 2014), la participación de lo técnico en nuestra experiencia del mundo.

Siendo tan sincrónicos el mundo y lo técnico, lo que valoramos en el trabajo de Sergio es su particular reticencia a sentarse en el lugar del observador (objetivo) y más bien dejarse tentar por la perspectiva del televidente, del fanático, del lector. $\mathrm{Si}$, aroma del tiempo, lo técnico ya enlaza las continuidades del mundo, esto lo que significa es, al menos, dos cosas. Por un lado, que, estando todo nuestro mundo permeado por la técnica, tanto más da estudiarla del lado de la emisión o de la recepción porque la aparente distancia entre ambas se desenvuelve, finalmente, en un mismo entorno: el sensorium. ${ }^{4}$ Por el otro, que abandonar el lugar de la observación neutral no es un gesto de falsa humildad, sino, en efecto, la más decidida de las apuestas epistémicas: en ellas trasluce una convicción según la cual el mundo

4 A caballo entre el aura benjaminiana y la perceptiva mcluhaniana, Sergio exploró ampliamente esta categoría (Roncallo-Dow, 2008b, pp. 107 y 108; 2011b, p. 130; 2015, p. 166). 
discurre conforme a los aparatos por los que el mundo se hace todo lo que viene al caso (Wittgenstein, Tractatus, $\$ 1$ ).

En efecto, al decir de Scolari, "los receptores no confrontan los mensajes con los códigos, sino más bien con un conjunto de prácticas textuales que son parte de su experiencia" (Scolari, 2015, p. 1039), de forma que, al vernos abocados a la necesidad de nuevas formas de escribir, captamos en el suelo (o en el pasado) los fragmentos rotos de un mundo que se evanesce. Siendo la tarea de una filosofía de la técnica interrogarse la dinámica de estos cambios, su tamiz ontológico, su textura cosmológica, por lo que es en la perspectiva de la comunicación en la que esta pregunta se asume desde las reconfiguraciones de sentido que ocurren en el ámbito de los usuarios.

Allí, en tanto materializaciones del sentido, surge un escenario privilegiado para dar cuenta de esa "secuencia de operaciones técnicas de las que se desprenden propiedades materiales del discurso" (Verón, 2013, p. 145). Dicho de otro modo, los cambios, ocurridos por la incursión de nuevos dispositivos, invitan a nuevos formas de producción del discurso, en tanto exigen reacomodos cuando estos prorrumpen el espacio social con formas-otras de interacción, acomodación de los mensajes, y, en últimas, re-estructuración del mundo, con lo cual se puede afirmar sin ambages que estas nuevas incursiones generan nuevas formas de hablar, esto es, de producir sentido.

Por este camino, cercano al sensorium benjaminiano, y (tentados estamos a decir) por tanto, distante a las lecturas disciplinares (que a menudo parten de las premisas epistémicas que exigen la partición del sujeto — empírico-y el objeto de estudio), Sergio nos invitó siempre a eliminar la postura que ubica al investigador en el lado de la supuesta observación objetiva y al objeto como unidad de análisis que se pudiera llevar a un laboratorio para ser visto por las mirillas de los aparatos. En cambio, no solo invitó a una exploración inspirada por Benjamin y McLuhan, sino que él mismo abordó la sonda mcluhaniana y se adentró, siempre en términos exploratorios, en la más variada gama de fenómenos del presente, para sumergirse dentro de las ondulantes movenciones de los fenómenos. 
Como gesto, la escritura de Sergio acoge un particular modo de desplegarse en el que los objetos no están previamente definidos en los tesauros ni en las formas de aproximación están mapeadas en los manuales de metodología. Este gesto, que recibe en el centro de su corazón el legado de Heidegger (en el sentido de entender al ser como un ser ya siempre en situación), abraza al mundo (es decir, con Wittgenstein, todo lo que viene al caso) de una forma en que la sonda de McLuhan se encuentra dirigida a aquilatar los procesos comunicativos como espacios de configuración de sentido; y sentido deviene todo lo que se puede nombrar ("taguear") en el mundo.

Así, la inquietud por lo técnico supera con creces la cartografía de los objetos técnicos que, como la espuma en nuestras manos, según el poema apotegma de Barba Jacob, pasa a resituarse como pregunta por los mundos posibles que se abren a cada dispositivo. Esto significa un interés permanente por aproximarse a la comprensión de cómo las tecnologías han venido atravesando la vida contemporánea para proponer narrativas sobre la memoria y las formas de saber que tejen/destejen los entramados sociales; de ahí la necesidad de comprender sus relatos y sus modos de relacionarse con el mundo de modo cognitivo, emocional, estético, moral y político.

Una reflexión así es tanto más necesaria en estos tiempos, in-definidos por la velocidad (Roncallo-Dow y Uribe-Jongbloed, 2017), la inestabilidad identitaria (Fierro y Roncallo-Dow, 2014) y las constantes transformaciones políticas (Roncallo-Dow, 2008b), sumas que afectan de manera vertiginosa las dimensiones de lo social-comunicativo; con movimientos casi telúricos en la política, la economía, lo ético-estético, ellas reorganizan el mapa social y, con ello, la existencia en y de la cultura. Hoy, la inauguración de una nueva forma de producción de la información hace que el tiempo se triture en la instantaneidad; velocidades de circulación que desvertebran de manera voraz las esferas de la vida tal y como la concebíamos. Ese nuevo entorno modula en digital, transcurre en electrónico, deviene virtual.

Por tanto, cuando se relee lo tecnológico en los múltiples textos de Sergio, se realiza un acercamiento más a la relación que se origina con el sujeto que a las tecnologías mismas. Su potencialidad se instaura justamente 
porque estas logran entrar en una sintonía con otros estratos de lo cultural que establecen un tipo de episteme que fragmenta la conocida. Sobre esta misma línea, discute que "la lectura debería ser hecha desde otro ángulo pensando el trabajo mismo del mito (de la tecnología) como imbricado en los procesos de complejización del sistema técnico que, en tanto estructurante y estructurado sostendría el modo mismo de dar cuenta del propio mundo" (Roncallo-Dow, 2011a, p. 136).

Esta propuesta suscribe el hecho de que la tecnología desborda la instrumentalidad para entrar en el terreno simbólico-cultural y ubicarse de manera osmótica en las instancias del mundo de la vida, para allegar los campos de producción de las subjetividades:

La tecnología involucrará, entonces, un modo particular de acercarse y comprender el mundo que ella des-vela ante el hombre y que el hombre habita en una suerte de relación mutua. Se sostiene así que la tecnología es la continuación de la vida por otros medios que la vida [las cursivas son nuestras]; se recuerda de algún modo, el apotegma orteguiano según el cual sin la tecnología el hombre no existiría ni habría existido de algún modo. (Stiegler, 2002, citado por Roncallo-Dow, 2011a, p. 43)

Por tanto, la tecnología debe ser comprendida como un tipo de saber: uno fundado en la téchnē y en la logía, esto es, un logos: una manera de saber. Se debe resaltar que todo saber está expuesto a una red de escenarios contextuales que le otorgan su sentido social; por estos contextos discurren condensaciones de significación que orientan y ayudan a la interpretación del saber. Téchnè y logos sueltan una dimensión indisoluble de la comprensión de las tecnologías y de los contextos en los que operan; las tecnologías son entonces una arista de los tiempos que se viven en un periodo determinado de la historia.

Las destrezas de las tecnologías en tanto téchnē bien establecen un tipo de público, bien establecen un tipo de productor. Este vínculo, más que una estrategia de comunicación, es un pacto que se crea para lograr un paradigma de orden social, una configuración comunicacional y, por ende, "una experiencia diferente de la vida cotidiana" (Stevenson, 1998, p. 17) 
que transita en las estructuras institucionales que las producen y las distribuyen. Visto así, las destrezas en tanto téchnē son una propuesta de vinculación con la realidad que conlleva un logos que relaciona los sujetos, los procesos socioculturales y las economías. Usar una tecnología es hablar una lengua.

Ahora bien, el saber que circula en las tecnologías en tanto logos implica que se debe conocer, más que su funcionamiento, sus potencialidades cognitivas, estéticas, éticas y performativas; se debe conocer en tanto tecnología. Así, dicho logos — concebido como medi-tación, como ese pensamiento social - descifra los cambios y las rupturas que se generan desde y por las tecnologías. Más que destrezas, el logos alude a una lógica de actuación, recepción y re-producción del saber social, que afecta de manera sistémica (pero no homogénea) las producciones de información, las relaciones sociales y las narrativas con las cuales se inventa el mundo. Por eso, el chat, el paper o el libro co-implican diferentes juegos de lenguaje.

¿Qué son entonces las tecnologías desde esta re-configuración conceptual? Sergio fue insistente: saberes que producen modelos de ciudadanías, de políticas, de economías, de subjetivaciones; una dimensión compleja de/ con otros estratos que operan transversalmente en la denominada vida social. Son, asimismo, culturas, sensibilidades sobre el mundo, que producen pactos culturales que sobrepasan la infra y la super-estructura, pues provienen de sus relaciones y, al tiempo, las reconvierten. Visto esto, las tecnologías inauguran nuevas prácticas sociales en las que emerge una representación nueva del mundo.

Por qué entonces las tecnologías están imbricadas en el mundo sino por su condición de tornados por los que se vierte el espacio-tiempo social. Su dinámica temporal viene pautada por los ritmos en los que se producen los intercambios de información, mientras que su textura temporal aflora por las dimensiones en que posibilitan las interacciones. Espacialmente, por ejemplo, Twitter opera como una ciudad, con barrios, callejuelas y parques (Roncallo-Dow y Mazorra, 2015); Instagram surge como álbum móvil de memorias (Jiménez y Roncallo-Dow, 2020); YouTube como archivo (Roncallo-Dow et al., 2016); y el videoclip como mito, esto es, como 
proyección externa del espacio interior (Roncallo-Dow y Uribe-Jongbloed, 2017). Temporalmente, por ejemplo, Twitter sigue la lógica de la conversación, Instagram la de lo transitorio, YouTube la de lo memorable y el videoclip la de la yuxtaposición de la vida en las urbes modernas.

Así es como, en tanto configuradoras de mundos, por el lado de la temporalidad, habría que interrogarse la rítmica que ellas instalan. Si la modernidad aparecía como un entorno más veloz que sus épocas precedentes, la escritura marcaba una impronta lineal; por eso, Sergio releyó en varias claves la literatura moderna, iluminado por las fragmentarias escrituras de Benjamin, cuya fugacidad, captada justamente al nivel del transeúnte, percibía los aromas de esa época en que las figuras literarias fueron pasando de los libros a los carteles colgados en los pasajes (Roncallo-Dow y Mazorra, 2015).

Con respecto a la espacialidad, habría que revisar cómo las tecnologías devienen un proceso de luchas y tensiones entre significados y sentidos que viven en múltiples espacialidades: laborales, de goce y disfrute, de ensoñación, de ritualización; retículas dentro de dimensiones y estratos culturales que van consolidando rituales emergentes que sostienen las prácticas sociales establecidas. Esto pone de relieve que toda espacialidad, en tanto articulación con las tecnologías (y como resultado de las tecnologías), es un lugar frágil, transitorio y dinámico, tanto como estable, sólido y dominante (según la lectura diacrónica o sincrónica que se quiera hacer), en que las tecnologías localizan las movilidades de la historia, las formas de ruptura - de fuga- que pueden modificar las estructuras sociales, los devenires de la realidad.

La espacialidad vista como tecnología permite comprender cómo y bajo qué formas las relaciones sociales se van modificando, se van solidificando. Recordemos que toda forma social está inscrita en una coordenada espacial que posibilita las significaciones con las cuales se designa el mundo; establece los códigos con los cuales este se condensa y, en consecuencia, los sentidos con los que se (da) cuenta. De suerte que el sujeto termina siendo parte de la dinámica de la producción social, como también resultado de las tecnologías y sus tensiones. Por esto, el sujeto no está fuera de la 
tecnología como una suerte de creador consumidor. El sujeto es visto como producción histórica que afecta y es afectado por la dinámica tecnológica.

En suma, esto propone la necesidad "de pensar la complejización del sistema tecnológico en la era de la telecomunicación y cómo desde la imbricación intersistémica lo que se despliega son toda una suerte de cambios que afectan, precisamente, el modo en el que el sujeto comprende el mundo y se relaciona con su entorno" (Roncallo-Dow, 2011a, p. 90). Dicha complejización, entonces, viene en clave espacio-temporal que permea las modalidades en que el mundo surge como un plexo donde se des-envuelve lo humano. Como dijimos, las tecnologías bruñen los hilos en que se teje el mundo, y de esto hay que dar cuenta implicándose en la experiencia espacio-temporal que ellas instauran.

Dicho lo cual, queda decir que, con respecto a la temporalidad, una de las dinámicas que estudió con especial interés Sergio fue la aceleración y la no linealidad desde donde estudió el videoclip como una aceleración del tiempo lineal del cine, en tanto este era ya una aceleración de la temporalidad fotográfica; con respecto a la espacialidad, una de las claves que investigó fue la condensación y la acumulación, desde lo cual pensó el cine como una acumulación de imágenes fotográficas (guiado por Benjamin) y el videoclip como una acumulación de imágenes cinematográficas.

Un programa de investigación armado con tales características asume que estas relaciones están presentes en la vida cotidiana, hacen parte de las prácticas que emergen en la informalidad, se encuentran en las formas de las narrativas contemporáneas y en las prácticas académicas, se materializan como prolongaciones del mundo tecnológico que se habita más como tecnología y menos como técnica (como forma de episteme que desborda la instrumentalidad) y se instaura como forma de pensamiento y por tanto de performatividad.

La construcción social de la realidad hará de los medios tecnologías máquinas socioepistémicas que tanto arrojan luz como oscurecen procesos sociales, y generan saberes que permean los modelos cognitivos de los grupos sociales, sus formas de circulación de saberes producidos por es- 
tos: "cada vez que una narración pasa de una tecnología a otra tecnología, las representaciones también cambian” (Lull, 1995, p. 32). Sobre esta misma línea afirmamos que los medios, las tecnologías y las representaciones que flotan en ellas son "una actividad social productora de redes semánticas, que repercuten y se dispersan sobre diferentes materias sígnicas para hacer un llamado a la propia existencia. Es desde estos dispositivos donde se configura y se 'echa a rodar' el sentido con el que negocia la subjetividad y los procesos que la determinan" (Murcia, 2015, p. 141).

Asido como un pensar-el mundo, el trabajo del investigador surge, pues, como una actitud performática. En sus papers y libros, Sergio traduce esta tarea como ejercicio de deconstrucción en el que los conceptos no están por sí mismos listos para usar, sino que requieren un ejercicio de adecuación para que sirvan en el propósito de entender, filosóficamente, los procesos comunicativos; en los chats, los conciertos y las tertulias, esta actitud aparece como un acting, una puesta en escena de los juegos de lenguaje (Roncallo-Dow y Mazorra, 2015, p. 155).

Haremos un breve excurso por esos juegos del lenguaje, de cuyo testimonio dan cuenta las múltiples emociones que hoy nos produce releer esos chats en los que armábamos selecciones de fútbol con filósofos, entendíamos las power ballads como compendios de aforismos comunicativos y, no pocas veces, nos quejamos de no poder incluir emojis y gifs en los textos que estábamos escribiendo con miras a su publicación.

\section{Nombrar a Benjamin: +lenguaje, -lexicografía}

Dijimos antes que desde la mano hasta el lenguaje el hombre ha llegado a ser lo que es por su capacidad de producir artefactos que extienden su mundo. Sin duda, el Heidegger que indagó la morada del ser como un constructo humano, el Wittgenstein que reconoció los límites del mundo como equivalentes a los límites del lenguaje y el McLuhan que en la idea de los medios como entornos cifró los términos del devenir histórico de la humanidad se dan la mano para alimentar esa ideas que, como riffs de guitarra, acompañaron las reflexiones de Sergio. Sin embargo, valdría decir que uno de sus talentos especiales consistió, justamente, en no usar los apoteg- 
mas o los aforismos como riffs (esto es, como frases guitarra que se repiten a lo largo de las canciones), sino como licks, es decir, como secuencias de notas que, a través de variaciones, agregaciones y alteraciones, sirven para tocar los solos de guitarra, los momentos en que el músico se suelta del rol rítmico-acompañante para dibujar en su línea melódica el devenir subjetividad que se recorta en el contexto de la música.

Sin duda, uno de los riffs (clichés, estereotipos) que Sergio moduló en licks fue lo de "el medio es el mensaje"; otro el de "los límites del lenguaje significan los límites de mi mundo", famoso single de Wittgenstein. En vez de limitarse a repetir estas tesis como frases (cerradas, unívocas, pre-definidas) en sus trabajos, homenajes a la morada heideggeriana, el aura benjaminiana, el mundo wittgensteiniano y la ecológica mcluhaniana, Sergio probó desde ellos una fraseología (una propia forma de hablar) mediante aperturas, vivisecciones, in-versiones, re-versiones y contra-venciones provocadoras. Así, la mirada sobre el mundo y el lenguaje dimitía de la posible restricción de Wittgenstein del lenguaje como palabra, para llevarla a catalejo de verdaderos happenings, esto es, como actos lumínicos de des-cubrimiento mediante la acción en con-texto. Esto nos anima a aventurar que, sin duda, el medio es el lenguaje; es decir, que la noción de medio que Sergio abordó en sus trabajos, a partir de los apotegmas de McLuhan, equipara las tecnologías como formas de hablar, de producir sentido.

Pero, además de la herencia del canadiense, en esta acepción ocupa un lugar central Benjamin, de quien Sergio admiró su descentramiento academicista y el hecho mismo de que en la aparente fragmentación benjaminiana (que acusara Adorno con recelo; cfr. Adorno, 1970) profiere más una decisión que una carencia. Para abordar esta relación tecnologías-mundolenguaje, es necesario volver a los clásicos (guiño), volver a Benjamin, no sin antes advertir que si hoy el alemán ya se puede contar dentro de los clásicos del pensamiento (no solo en comunicación) es gracias a que sus ideas sobre aura, fotografía e historia se han ido congelando, es decir, han devenido riffs. Sergio nunca quiso ocultar su animadversión (en chats nos diría "resquemor") contra esas lecturas manieristas que propicia el academicismo formalista; en cambio, nos concitó a deshacernos de esa visión que quiere acomodar a Benjamin en el cajón de los precursores de la escuela de Fránc- 
fort o, mejor dicho, en el canon de pensadores críticos cuyo sistema categorial es digno de exponerse en los manuales de comunicación al uso. Si algo le despertaba interés tanto en Benjamin como en McLuhan, fue justamente esa condición extra-territorial, esa convicción anti-doctrinal y, por sobre todo, su actitud de exploradores.

Los conceptos que iluminan este argumento que busca asociar las ideas de mundo, tecnología y lenguaje están bañadas por el bálsamo de las nociones de Benjamin (2018) sobre el lenguaje. No es casual que el pensador haya dedicado algunas páginas a la comprensión "de toda expresión de la vida mental y espiritual humana” (p. 23). Trayendo su concepto de lenguaje como un todo fundante, se comprende, entonces, que "cada comunicación de contenidos espirituales e intelectuales es lenguaje y la comunicación por medio de la palabra constituye un caso particular del lenguaje humano, de su fundamento o de aquello que sobre él se funda (como la justicia o la poesía)" (p. 23).

Es claro cómo las actividades intelectuales y espirituales de la humanidad están determinadas por una anterior que es el lenguaje, puesto que "no se extiende sobre todos los "ámbitos de la expresión mental del ser humano, sino que se extiende sobre absolutamente todo". Esta idea de lo absoluto no tiene que ver con una mirada lingüística de las prácticas humanas (que como bien propone el autor, son una tautología), sino que sugiere una perspectiva más abarcante de las funciones y las actividades de la cultura misma de las que se desprende un modo de habitar (en) el mundo social. Así, se podría argüir que la idea del lenguaje es "la búsqueda de la necesidad en la experiencia subjetiva” (Verón, 2013, p. 74). ${ }^{5}$

Las ideas del lenguaje propuestas por Benjamin (2018) como generadoras de un marco de comprensión social son más que signos. Se convierten en una serie de diálogos intra-y extra-contextuales con distintas modalidades de nombrar en las que unas se explican a otras a través de traducciones, dispositivo que se percibe como "la transferencia de un lenguaje a otro a través de un continuo de transformaciones" (p.34), que poco o

5 Más allá, incluso, Sergio exploró el habitar como hablar (Roncallo-Dow, 2011a, pp. 196-220). 
nada tienen que ver con entidades semejantes, sino que a través de este se va re-creando mediante formas y maneras de habitar y de conocer.

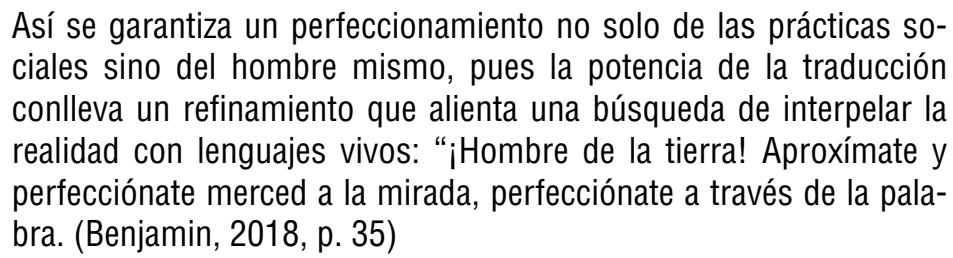

Este pasaje, citado por Benjamin a propósito de El primer despertar de Adán y sus primeras noches bienaventuradas, del pintor Müller, evoca perfectamente la transformación que se genera en virtud del dispositivo de la traducción: la relación entre el mirar y la palabra invita a ver eso que Blake invocaba en (palabras de McLuhan) la transformación de los órganos de la percepción; si estos varían, parecen variar los objetos de la percepción.

Nos encontramos en medio de un diálogo entre Benjamin y McLuhan sobre las tecnologías y cómo estas se extienden en diferentes contextos sociales. Cabe resaltar en este punto cómo la definición de traducción tiene un emparejamiento con la definición de los medios en tanto traductores, propuesta por el profesor canadiense: los medios como extensiones del cuerpo humano se convierten en dispositivos en lo que "todo puede ser almacenado y transferido" (McLuhan, 1996, p. 78) y, por tanto, los medios como tecnologías traducen las experiencias humanas en superficies materiales con las cuales se retiene y se recupera el mundo.

Sobre esta línea de Benjamin, Sergio se acerca a una lectura mediática de este dado que su interés es poner en evidencia "los modos en el que el hombre se apropia de su entorno" (Uribe-Jongbloed y Roncallo-Dow, 2013 , p. 186) y las relaciones que se establecen a partir de esta relación. Así, distante de procesos estructuralistas o lingüísticos, Benjamin ya establece una lectura ecológica del lenguaje, "pues es entonces la entidad espiritual de las cosas" (2018, p. 29) en la que el lenguaje carece de contenido; el contenido de todo lenguaje es otro lenguaje. ¿El medio es el mensaje? Benjamin (1996) parece comprender la idea de que lo importante del lenguaje es eso que McLuhan denominaría las "consecuencias mentales y sociales de 
los diseños o esquemas en cuanto amplifiquen o aceleren los procesos existentes" (p. 34). Los efectos a niveles psicológicos y sociales de las tecnologías ya están presentes en la definición del pensador alemán.

La lectura de lenguaje sobrepasa la idea misma de canal o medio; su claridad con las implicaciones psicológicas y sociales del lenguaje lo llevaron a concebirlo como medium de la comunicación. Lo importante no es el contenido de la práctica de comunicación, sino el lenguaje mismo, a saber: "el nombre puede ser considerado el lenguaje del lenguaje (siempre y cuando no indique una relación instrumental sino 'medial' — medium-)" (Benjamin, 2018, p. 28). Es decir, que con esta implicación medial se garantiza la función sustantiva del lenguaje: "El nombre, como herencia del lenguaje humano, asegura entonces que el lenguaje es la entidad espiritual por excelencia del ser humano y, por ello, solo la entidad espiritual y mental de los humanos es la única íntegramente comunicable entre todas las entidades espirituales" (p. 29).

En esta misma línea, la diferencia que se encuentra en los lenguajes está determinada en tanto medium que "por así decirlo se diferencian en densidad y, por tanto, de un modo gradual" entre ellos; la densidad y lo gradual del lenguaje (como tecnología) se establece no del mismo lenguaje, sino de su relación con otros para amplificar, generar o modificar usos y construcciones de sentido; lo que los diferencia es la manera como ellos convergen en determinadas tecnologías para generar distintos resultados. A esto McLuhan (1996) lo discutía así: "los efectos de las tecnologías no se producen a nivel de las opiniones o de los conceptos, sino que modifican los índices sensoriales o pautas de percepción, regularmente y sin encontrar resistencia" (p. 39).

¿Qué se comunica en el lenguaje? Es la pregunta central del capítulo de Benjamin; y la que se convierte en un eje primordial para comprender las tecnologías como enhebradoras del mundo. Lo que se comunica es el lenguaje a sí mismo, en sí mismo; es el mismo medium de la comunicación, pues todo se "comunica en el lenguaje, no por medio del lenguaje" (Benjamin, 2018, p. 24). Traductor de experiencias para aprehender el mundo, para comunicar el mundo y para relacionarse con el mundo (siempre a tra- 
vés de otro lenguaje), lo que se comunica en el lenguaje son las transformaciones humanas resultado de su ligazón con las cosas, dado que el ser humano es lenguaje. Por tanto, ni tecnologías, ni lenguajes, ni mundo son externos a lo humano; son su límite, si se quiere, inferior y superior (sin las implicaciones metafísicas que incluya asociar lo superior o lo inferior a nociones morales); son los lindes en los que lo humano es posible, los nodos que marcan la amplitud y las modulaciones de sus posibilidades.

La definición de lenguaje anclada a la mirada ecológica permite comprender la convergencia no solo como un encuentro de lenguajes tecnológicos, sino como un entrecruzamiento de distintos juegos del lenguaje que van estableciendo modos de participación en la cultura, al tiempo que reorientan las maneras de comunicar y percibir el mundo; de esta forma, pensamos que en la medida en que van apareciendo nuevas maneras de narrativizar la vida social, fruto de la tecnología, se van reagrupando los sentidos mismos de la realidad en los niveles social y psíquico, de manera que sus derivaciones no solo son del orden discursivo o superficial: "sus efectos no se producen a nivel de las opiniones o conceptos, sino que alteran los ratios del sentido y los patrones de percepción de manera constante y sin ningún tipo de resistencia” (McLuhan, 1996, p. 31).

Con todo, un encuentro de la tecnología como modulador de la experiencia y del lenguaje como entorno humano son invitaciones que a lo largo y ancho de la obra de Sergio invitan a jugar; quien juega busca a otro para extender su performática trayectoria por el mundo, incita al reconocerse mediante el nado más que a través de la tranquila seguridad del muelle.

\section{Des-pedir, ese verbo}

La partida de Sergio nos produjo ese entumecimiento del que hablara McLuhan (Roncallo-Dow, 2011b); Sergio mismo, todo (lo de) él, su vida, era un entorno, una plataforma para pensar-en-el-mundo, una subjetividad conformada desde la pregunta, una constante performática. Leer a Sergio, conversar con él, será siempre una aproximación a un ser-investigador que nos ayuda a entender el mundo como configuración de la tecnología, la tecnología como lenguaje, el lenguaje como posibilidad del mundo y el mundo como una pre-ocupación humana. 
Ahora nos queda vivificar ese legado, en el que conversan las canciones que tocamos, las lecturas que compartimos, las fiestas que inventamos y esas micro-ritualidades del chat en las que día tras día surgieron categorías emergentes desde las que hoy intentamos organizar nuestra experiencia en el mundo. Este texto, que es un chat con invitados, es nuestro homenaje. Sabemos que no nos dejará en visto.

\section{Referencias}

Adorno, T. W. (1970). Sobre Walter Benjamin. Cátedra.

Barba Jacob, P. (2011). Canción a la vida profunda. Universidad Externado de Colombia.

Benjamin, W. (2018). Iluminaciones. Taurus.

Deleuze, G. y Guattari, F. (2006). ¿Qué es la filosofía? Anagrama.

Fierro Valbuena, A. y Roncallo-Dow, S. (2014). Entre porosidad y blindaje: el devenir de la subjetividad. Discusiones Filosóficas, 15(24), 201 219. http://www.scielo.org.co/pdf/difil/v15n24/v15n24a11.pdf

González-Bernal, M. I., Roncallo-Dow, S. y Arango-Forero, G. (2018). Estudiar las audiencias: tradiciones y perspectivas. Universidad de $\mathrm{La}$ Sabana. https://doi.org/10.5294/978-958-12-0482-3

Jaramillo, D. (2008). Poesía en la canción popular latinoamericana. Pre-Textos.

Jiménez Rodríguez, J. y Roncallo-Dow, S. (2020). Good old-fashioned lover boy: Instagram, la memoria y la mutación. En C. Arango \& D. González (Eds.), Sensibilidades, interacciones, mediaciones. Universidad Católica de Oriente.

Lull,J. (1995). Medios, comunicación, cultura: aproximación global. Amorrortu. 
McLuhan, M. (1996). Comprender los medios de comunicación: las extensiones del ser humano. Paidós.

Murcia Quiñones, H. (2015). Cuerpo y modernidad en Colombia durante la década de los cuarenta: aproximación desde la revista Cromos. Forma y Función, 28(1), 137-155. https://doi.org/10.15446/fyf. v28n1.51975

Roncallo-Dow, S. (2008a). El juego de la distancia: entre la significatividad y la recepción: un viaje por los prometeos de Blumenberg. Universitas Philosophica, 25(51), 59-83. https://www.redalyc.org/ pdf/4095/409534415004.pdf

Roncallo-Dow, S. (2008b). Por una re-partición de lo sensible: disensos y aperturas de nuevos espacios: una lectura de la estética y la política en J. Rancière. Signo y Pensamiento, 27(53), 104-127. https:// revistas.javeriana.edu.co/index.php/signoypensamiento/article/ view/3722

Roncallo-Dow, S. (2011a). Más allá del espejo retrovisor: la noción de medio en Marshall McLuhan. Pontificia Universidad Javeriana.

Roncallo-Dow, S. (2011b). Medios, antimedios, sondas y clichés: revisitando a Marshall McLuhan, el explorador. Signo y Pensamiento, 31(59), 122-138. https://www.redalyc.org/pdf/860/86022458009.pdf

Roncallo-Dow, S. y Mazorra, D. (2015). Lenguajes, tweets y pantallas: entre escrituras y visualidades. Cuadernos de Música, Artes Visuales y Artes Escénicas, 10(2), 153-169. https://doi.org/10.11144/Javeriana.mavae10-2.ltpe

Roncallo-Dow, S. y Uribe-Jongbloed, E. (2017). La estética de los videoclips: propuesta metodológica para la caracterización de los productos audiovisuales musicales. Cuadernos de Música, Artes Visuales y Artes Escénicas, 12(1), 79-109. https://doi.org/10.11144/ Javeriana.mavae12-1.evpm 
Roncallo-Dow, S., Uribe-Jongbloed, E. y Goyeneche-Gómez, E. (2016). Volver a los clásicos: teorías de la comunicación y cultura pop. Universidad de la Sabana.

Scolari, C. (2015). Los ecos de McLuhan: ecología de los medios, semiótica e interfaces. Palabra Clave, 18(4), 1025-1056. https://doi. org/10.5294/pacla.2015.18.4.4

Sibila, P. (2013). El hombre posorgánico: cuerpos, subjetividad y tecnologías digitales. Fondo de Cultura Económica.

Stevenson, N. (1998). Culturas mediáticas: teoría social y comunicación masiva. Amorrortu.

Uribe-Jongbloed, E. y Roncallo-Dow, S. (2013). El medio es el mito: entre McLuhan y Barthes. Universitas Philosophica, 30(61), 177-203. https://revistas.javeriana.edu.co/index.php/vniphilosophica/article/view/10642

Verón, E. (2013). La semiosis social. Vol. 2: Ideas, momentos, interpretantes. Buenos Aires, Argentina: Paidós. 